\title{
6A very complicated version of freedom' Conditions and experiences of creative labour in three cultural industries
}

\section{David Hesmondhalgh, Sarah Baker}

\section{Introduction}

A number of studies of artistic labour, based primarily on survey data, have generated clear findings. This research suggests that artists tend to hold multiple jobs; there is a predominance of selfemployed or freelance workers; work is irregular contracts are shorter-term, and there is little job protection; career prospects are uncertain earnings are very unequal; artists are younger than other workers; and the workforce appears to be growing (see Towse, 1992; Menger, 2006 for valuable summaries of a range of studies). 'Artistic' here means the subsidised arts sector, but these features would seem also to apply very much to artistic (and informational) labour in the cultural and creative industries, especially given changes in these industries over the last twenty years tha have seen increasing casualisation and short-term contract working. If that is so, then policies that argue for the radical expansion of these industries under present conditions, as 'creative industries policies' do, without attention to the conditions of creative labour, risk generating labour markets marked by irregular, insecure and unprotected work. This means that as well as the intrinsic importance of studying the quality of working life in these growing industries, there is also a policy reason to do so.

However, there has been a somewhat surprising lack of qualitative studies of working conditions in the cultural industries (as opposed to the working conditions of more narrowly defined artistic workers - see Shaw, 2004) and of the experiences of cultural workers. While there is a rich tradition of research on the political-economic dynamics and organisational structures of these industries (e.g., Miège, 1989; DiMaggio, 1977; see Golding and Murdock, 2005, and Hesmondhalgh, 2005 for summaries), surprisingly few analysts have addressed questions of labour specifically (the major exception is Ryan, 1992). In recent years, sociologically informed writers have begun to fill this gap. For example, using diary data, Paterson (2001) compared career patterns amongst three age cohorts of workers in the television industry, and noted the profound uncertainty that had entered the lives of television workers with the technological and organisational changes of the 1990s. Also studying television, and concentrating on the freelance workers who form the majority of the labour force, Ursell (2000) analysed the way that these workers had in effect to organize their own labour markets. Blair (2001) showed how entry into the UK film industry was highly dependent on social networks (cf. the earlier work of Faulkner and Anderson, 1987, on Hollywood) and that work there was intensive, demanding and highly interdependent.

Ursell's research was significant because it paid attention to the particularly high levels of personal investment in cultural labour - somethin that had increasingly been noted by sociologists of work concentrating on other fields (such as Kunda, 1991), building on groundbreaking studies of 'consent' (such as Burawoy, 1979). Ursell acknowledged that processes such as union derecognition and considerable reduction in labour costs and earnings provided plenty of evidence to support a Marxist reading, focused on exploitation and property. But she also noted 'an intensification of the self-commodification processes by which each individual seeks to improve his/her chances of attracting gainful employment' (Ursell, 2000:807). This element of 'apparent voluntarism' needed to be acknowledged, she asserted, and Ursell turned to Foucauldian theory (such as Knights and Willmott, 1989) 'not to dispense with [labour process theory] concerns' but 'to approach them more substantially' (2000:809).

Angela McRobbie (2002:517) followed by offering 'a preliminary and thus provisional account' of how notions of creativity, talent and work are being redefined in those burgeoning micro-businesses of the cultural sector associated with young people, including fashion and design, but also entertainment industries such as clubbing, recording and magazine journalism. She echoed Ursell in pointing to the 'utopian thread' involved in the 'attempt to make-over the world of work into something closer to a life of enthusiasm and enjoyment' (McRobbie, 2002:523), but also in focusing on how this leads to a situation where, when things go wrong, young people entering these creative worlds of work can feel they only have themselves to blame. In this respect, McRobbie usefully broadened the study of cultural work to include a wider set of conditions and experiences, including the way in which aspirations to and expectations of autonomy could lead to disappointment and disillusion.

Such questions of quality of life and dynamics of 'self-exploitation' have also been investigated by writers such as Andrew Ross (2003) and Ros Gill (2002) in relation to culture-related industries such as IT. Writing about work in the IT sector (a form of work sometimes unhelpfully blurred with artistic labour in the notion of creative industries) Ross observed how, in the eyes of a new generation of business analysts in the 1980s, Silicon Valley 'appeared to promote a humane workplace not as a grudging concession to demoralized employees but as a valued asset to production' (Ross, 2003:9). 'New economy' firms, he argued, aimed to provide work cultures that 'embraced openness, cooperation and self-management' (Ross, 2003:9). But this, showed Ross, was closely linked to long working hours and a serious erosion of the lin between work and leisure. Whilst the dot.com working environments offered 'oodles of autonomy along with warm collegiality' (Ross, 2003:17) they also enlisted 'employees' freest thoughts and impulses in the service of salaried time' (Ross, 2003:19).

These are only some of the contributions to studies of cultural work in recent years from sociology and related areas such as cultural studies. There is no space to offer a survey of this research here (and in any case Banks, 2007, has provided a comprehensive overview). Instead, we aim to build on that strand of research which seeks to explore the experiences of workers in cultura and media industries. We do so across a number of dimensions that have emerged in the sociology of work more broadly, and in these qualitative studies of cultural work more specifically. These dimensions are here grouped into the following three categories: pay, working hours and unions insecurity and uncertainty; socialising, networking and isolation.

Our research goes beyond the existing studies discussed above in a number of ways. First of all, we conducted interviews across three very different cultural industries. The three industries were selected because they represent examples of each of three different 'logics' of cultura production, identified by Miège in his influential 1989 account of different 'logics' or models of production in cultural industries (Miège, 1989): - Music as an example of the publishing model or logic (based on offsetting risk by producing a catalogue of repertoire, whereby inevitable failures are balanced out by occasional hits or successes - used in books, music, and film) - Television as an example of the flow model or logic (based on a continuous flow of product, and the gaining of audience loyalty, as in radio, television and new media).

- Magazines as an example of the written press model or logic (the regular and loyal consumption of a series of commodities, in newspapers and magazines)

A testing of Miège's classification was not our main aim. Rather, using these categories seemed the most effective way to draw upon existing classifications of the cultural industries to ensure a spread of examples of cultural work, including different working conditions. Second, recognising the integral importance of genre to cultural production, and therefore to cultural labour, we also interviewed workers in a range of genres within each industry: rock/pop, jazz and hip hop/electronic dance music in the recording industry, music magazines, men's magazines and the building/construction trade press in magazine journalism, and arts/history documentary, drama serials and 'factual entertainment' in television. A total of 63 interviews were conducted in England in 2006 and 2007, with between six and ten interviews undertaken for each of the genres under consideration. Interviewees ranged across the following characteristics: corporate and independent sectors; freelance and salaried staff; established creative personnel who have made their names in the industry, aspiring newcomers, and older practitioners; London-based workers and those in other locations in England; creative managers, marketers and creative personnel. We also conducted ethnographic fieldwork in a London-based independent television production company, which we report separately (see Hesmondhalgh and Baker, 2008) but refer to briefly here. Thirdly, our aim was to analyse more closely the emotional responses of cultural workers to their working conditions, insofar as these could be ascertained from fieldwork interviews. By 'emotional responses' we mean states of mind such as pleasure, enjoyment and anxiety. We focus on these experiences and emotional responses in order to register with greater clarity the effects of the working conditions of the cultural industries on cultural workers. This includes some of the pleasurable and autonomous aspects of cultural work, as well as its downsides. As is appropriate 
for qualitative research interviews, we emphasise subjective experience over generalisability, while paying close attention to the range of people we were speaking to, and the kinds of motivations they might have in presenting their views to us. We take seriously our interviewees' accounts but do not necessarily take what they told us at face value.

\section{Pay, working hours and unions}

We begin with what is widely considered to be the most crucial way in which workers think of their work: how much work they do, and how much they get paid for it. Striking here was the use of language which expressed anxiety about the sheer numbers of young people competing for work. One factual producer spoke of 'an army' of graduates from media and journalism courses (Interview 21) who, as a researcher at the BBC explained, 'can't expect to graduate and magically fall into a TV job because everyone knows how competitive the industry is' (Interview 35). A documentary production manager told us that 'hordes and hordes of kids ... will do anything' to get a position (Interview 43). And in our ethnographic research at a London-based independent television production company during the first half of 2007 workers expressed concern about their 'replaceability' - recognising, from their own experiences of job searching 'between' contracts, the sheer volume of young freelancers competing for the same pool of positions (see Hesmondhalgh and Baker, 2008).

\subsection{Pay}

This massive 'reservoir' (Miège, 1989:83) of labour means that wages are depressed, and in many cases workers - especially young people - are willing to work for free. In her study of the UK television industry Ursell $(2000: 814)$ writes of the number of university students on work experience who 'gift' several weeks of free labour to production companies in the hope that 'their gift will bring career returns in the future'. When many of these students graduate from their course, says Ursell (2000:814-815), they 'persist in working for nothing or expenses only, or cash-in-hand, or very low pay' and this then results in 'extremely low pay at the entry point to the industry'. Willis and Dex (2003:124) concur, saying that the labour supply is bursting with 'graduates willing to work for free or for very low wages to get a foothold in the industry'. One junior writer for a men's magazine, for example, told us that 'on the fashion desk load of them are working for free, up to a year and stuff, and people do work experience as writers for six months or so and they write for nothing' (Interview 12). In television the willingness to carry out unpaid or low-paid labour results, as one production manager of documentary films claimed, in 'abuses' of junior workers in companies producing reality and factual television: 'They don't get paid properly, but it's supply and demand

they kind of churn people out and spit them ou leaving the young workers 'battered and bruised' (Interview 43). Two metaphors conveying worker experience get mixed here, both disturbing in their implications. 'Churning out' workers invokes a sense of dehumanisation, 'spitting them out' suggests an animalistic gobbling up of workers, before they are rejected as inadequate for consumption. This chimes with Ursell's (2000:816) description of the television industry as a 'vampire, ingesting youngsters at low prices from a large pool ... working newcomers and established hands remorselessly, and discarding the older and less accommodating at will'

Some managers were keen to emphasise that their companies made a point of doing things differently. For example, one Head of Production in the documentary sector told us:

I know some companies keep them on because they think experience is a good thing and don't necessarily pay them. But we find if they are actually doing a job and they are contributing so much to a production and that we couldn't do without them, then I think we should pay them, and we do.... And we always pay expenses for work experience.' (Interview 40)

Note here, however, that these more reasonable conditions seem somewhat qualified. Only if the young people on placement are contributing so much that 'we couldn't do without them' will they actually get paid more than just expenses.

That so many workers, including graduates, are willing to sacrifice pay for a foot in the door has repercussions for those already working in cultura industries. As Ursula Huws (2006 - 2007:10) explains, when workers are 'putting in extra time, accepting lower pay or poorer conditions' they are 'either directly or indirectly ... constructing new bars for their own cages, or those of others'. The result, for one music writer (Interview 4) we spoke to, is that publishing houses have a sense that 'everybody wants to work for them' and, in the case of one particular company, become 'incredibly rude' and 'arrogant' towards their writers, treating them 'like plankton' (dehumanisation again). This engenders an uncomfortable feeling in workers that they are dispensable: 'there is pretty much always somebody to replace you and do your job', as one freelance music writer put it (Interview

41). And this in turn leads to greater pressure, and considerable self-consciousness about how workers might be perceived:

'I try not to refuse work whenever I can, because then people think you might be being a bit too - not full of yourself - but something like that ... because if they need somebody to do that, then there's no reason fo them to go elsewhere.' (Interview 41, music writer)

\subsection{Working hours}

According to Mark Banks (2007:36), being a flexible worker in the cultural industries: 'essentially means that one must do whatever is required to support commercial interests. It increasingly requires working longer or unsocial hours, taking onboard additional responsibilities, relocating according to

...there is a strong tendency
towards self-exploitation
in the cultural industries.
...But why do so many
young people want to work
in these industries, in spite
of the low rates of pay and
long working hours...

company demands and certainly committing oneself to the commercial imperatives of the firm over and above non-work commitments.'

This was very much confirmed in our research. One documentary camera operator explained how, in television, contracted working hours have extended, though without an increase in pay: 'On commercials you used to have an eight-hour day, that was your basic working day, and then after eight hours you'd be on overtime. Most commercials you did ten hours minimum anyway so you'd work two hours overtime and then production companies and budgets got tighter and they started saying your basic day is going to be ten hours. The same thing has happened in documentaries. We never had an eight-hour day; it was always a ten-hour day ... But now people are trying to be sneaky and saying your basic day is twelve hours, but instead of saying you are going to be paid for an extra two hours, you get the same pay for working twelve hours that you did for working ten hours, which effectively means that you take a pay cut.' (Interview 33)

However, as noted in Section 1, one of the problems for cultural workers is that they are often, at least on the face of it, 'free' to decide whether to take on such long hours. This has its pleasurable aspects. A manager in the music industry outlines the kind of working week that results:

'I tend to work six days and it tends to be mid morning to late evening. But the evening stuff is stuff that I tend to enjoy, seeing bands and artists and putting on gigs. I do a radio show as well; I forgot that. I do a monthly radio show on the local music scene. It's really varied which is lovely. I don't have a routine at all.' (Interview 19)

'Pleasure in work' (Donzelot, 1991; Nixon and Crewe, 2004), then, is closely linked to selfexploitation. For example, a reviews editor of a music magazine stated:

'I'm one of those people who really love being busy but then I risk taking on far too much ... and people presum you're going to do it and then you realise you've got no time to do it. I went to my boss and said, ... 'I'm going to have a breakdown one of these days because l'm working ridiculous hours and working on weekends and doing all this crazy stuff'. I enjoy it, admittedly, but when it starts affecting you, that's really bad.' (Interview 30)

Interviewees also told us of the physical dangers of working long hours, especially in television. One factual producer (Interview 27) spoke of a friend who after working extended hours on a regional shoot then had to drive back to London, exhausted, and ended up having a car accident. A cameraman told us: 'Crews do crash on the road sometimes because they get overworked and flogged and they drive off the road or they crash and even get killed occasionally, and that's because there's a lot of pressure' (Interview 29). Whether this is really the case or not, this worker can be understood as externalising his own fears about the pressure put upon him. Even as an established cameraman who tries to pace himself, say no and 'be sensible' he still finds there are 'times when you are downing Red Bulls or taking Pro Plus and things like that and you are shaking and you have to work the most ridiculous hours and you're in a terrible state, which you shouldn't really be in' (Interview 29).

Our evidence suggests that there is a strong tendency towards self-exploitation in the cultura industries. This may be a feature of a great deal of modern professional work. But why do so many young people want to work in these industries, in spite of the low rates of pay and long working hours that many of our interviewees reported, and which are confirmed in the survey data mentioned at the beginning of this article? Menger (1999:554) usefully distinguishes three different explanations for this phenomenon. The first is the labour of love explanation (Freidson, 1990) - artists, or symbol creators, have a strong sense of a 'calling', of potential fulfilment, and they are prepared to take the risk of failure. A second set of explanations emphasises that artists might be risk-lovers, or like lottery players, simply haven't considered properly how likely it is that they will fail (though success and failure isn't quite as arbitrary as in a lottery). A third explanation is that artistic work brings nonmonetary, psychological rewards, associated with autonomy, community, the possibility of self-actualisation, and potentially high degrees of recognition, even celebrity. McRobbie explores the political implications of such views of work, when she writes about the way that the ideal of self-expressive work is mediated by new rhetorics of mobility and success (McRobbie, 2002:101). This has implications, we would claim, for the degree to which cultural workers turn to unions for support.

2.3. Unions

What role can unions play in countering the problems of pay and working hours discussed above? As an official of the main UK broadcasting union (BECTU - the Broadcasting, Entertainment, Cinematograph \& Theatre Union) put it 'freelances arguably have more need of union support than do permanently employed workers' (in Saundry et al., 2007:182). Though this may be the case, the uncertain nature of freelance work and worries about where the next short- term contract will come from means unions are not on the radar of many cultural workers. This was born out in the interviews with music industry workers, none of whom spoke about the role of unions in the organisation, conditions or experience of their work.

With regard to the television industry, Saundry et al. state that, 'inexperienced workers, desperate for employment and keen to build their reputation, are unlikely to insist on [union] rates' (2007:182). In our research, a junior factual cameraman who had been on sequential, rolling short-term contracts with a regional factual company found his position frustrating because 'although I'm kind of treated as staff ... I'm just not paid like staff' (Interview 25). He works on a daily rate which does not specify the length of the day and although he knows BECTU sets out different wage brackets relating to hours worked he says he finds 
it 'difficult to go up to a production manager and say "I want that amount of money". His concern is that by asking for the BECTU rate 'you quickly price yourself out of the market' and the company would find themselves a new camera operator who would not charge the BECTU rate for the 90-h week. He believes that it would not be for another 20 years of working in the industry as a cameraman that his 'self-worth' would have risen to the extent that he will have the confidence to negotiate his pay with production managers. No wonder then that one young documentary producer (Interview 24) remarked 'if there's one place that should be unionised it's the TV industry. The exploitation is pretty severe'. Yet it was recently estimated that only one-third of UK television freelances are members of the broadcasting union BECTU (Carlyon, 2006:22).

Similar stories come from the magazine industry which, like the audio-visual industries was once heavily unionised. In a discussion of the impact of union derecognition in magazine publishing companies Gall (1997:157 - 158) posits there is a distinct correlation between derecognition and increasing incidence of 'lower starting rates, longer working weeks, the removal of overtime pay and various allowances, and reduction in holiday pay and redundancy pay'. Those most affected have been 'newly recruited full-time permanent staff, freelances and casuals ... because their terms are far easier to vary and worsen because of their relatively greater insecurity' (Gall, 1997:158). One key issue for freelance writers is their rate of pay per word. The NUJ (National Union of Journalists) promotes minimum rates but some of the freelances we spoke to were not aware what these were:

'There's a NUJ rate, but I can't remember what it is. It's a minimum rate and it's really miniscule. It's something like 240 pounds for 1,000 words. Not much. Unless it's 340 pounds? These are the sorts of things I should know as a freelancer but I don't.' (Interview 32, writer men's magazines)

In many ways the rate is a moot point because this writer foresees a similar problem to that faced by the junior cameraman: asking for the union rate could jeopardise getting future work by associating him with 'trouble'. Here again the problem of self-consciousness in an industry where individuals have to sell their reputation is apparent (see Section 2.1 above):

'The problem is that say l'd had a dispute with The Guardian [who had recently only paid him one third of what he thinks the minimum rate is], it could be that would get the union in, they'll be embarrassed, they'll pay me an extra 50 pounds for the money they should have paid, and then The Guardian would just never use me again - "he's a trouble making bastard". So, it's not worth my while for 50 pounds.' (Interview 32)

This is a view supported by another freelance writer for men's magazines who has never been a member of a union. Whilst unions may, as he says, 'look after your interests if you are being underpaid or stuff like that', in his experience 'editors just don't want to be bothered with that sort of stuff. They just say okay, fine, we'll pay you more, and then you never get any more work from them because it's just a freelance gig' (Interview 28).

A senior music writer (Interview 36) described how one way to overcome being underpaid is by forming a freelance collective. He talked extensively about the time he, along with other freelance music writers, lobbied a large publishing house where the union wasn't recognised in order to improve pay conditions. This 'was almost unique in the British media. A bunch of freelancers get together in a house where the union is not recognised and negotiating pay agreements for freelancers when there's no negotiation for staff' (Interview 36). But even this optimistic organiser notes that although the agreement regarding ratesper-word is currently in place it is at the whim of the company and 'can be cracked, and when we get a nasty manager it will all end' (Interview 36).

For the most part though, freelancers negotiate rates individually and as Dex et al. note, while on the one hand established workers have a strong position from which to negotiate their worth, on the other newcomers are 'weak players' chasing jobs on 'unviable terms' (Dex et al., 2000:285). The established freelancers we interviewed seemed more able and willing to negotiate rates. Note for example the assertive use of the first person in this quotation from one senior factual/documentary editor who told us:

'If people haggle about what they pay you, and people do, they say "I am this company and I want this, this and this", I just say well, "I am me and ... I charge what I charge for what I do"... . So I am quite straight in saying | am worth what I do.' (Interview 14)

However, for those still in the early stages of a freelance career, their negotiating stance was more likely to be dramatised in terms of a portrayal of the self as desperately needy:

'The higher up you get the easier it gets because you've got more contacts, you've got people who regularly ask for you and the higher they get they generally get to pick their programme.... But early on in your career you are thinking 'anything - now' because I've got to pay rent.' (Interview 31, factual assistant producer)

And it is not just rent that has to be paid. For as Ekinsmyth (2002:239) reminds us 'freelances are responsible for their own development and training, pensions and social security; and homeworking freelances are additionally responsible for their capital equipment, their accommodation, lighting and heating'.

Cultural workers seem torn over the precariousness of their work - bemoaning the mental and emotional states produced, but also resigned to insecurity, and prepared to speak of it as necessary and even desirable.

\section{Insecurity and uncertainty}

According to Murdock (2003:31) moves in the cultural industries 'toward outsourcing production, relying more on freelance labour, and assembling teams on a project-by-project basis, have combined to make careers in the cultural industries less secure and predictable'.

Researchers have noted how in television, for example, changes in regulation and developments in technology have 'increased uncertainty' for television workers since the 1980s and that these workers 'find uncertainty a problem; they dislike it and it causes stress for the majority' (Dex et al., 2000:283). Much of this uncertainty centres on concerns about gaps in employment. Given the short-term nature of most contracts, new work is constantly being sought. Job seeking is relentless, even during times of employment, 'in order to sustain sufficient employment and to maintain career progress' (Paterson, 2001:497). For Neff et al. (2005:319), the cultural industries are 'built upon workers being motivated by the promise of one Big Job being right around the corner' and also their 'willingness to take the periodic risk of being out of work along with the continual risk of investing in their careers'.

In this section, we concentrate on the mental and emotional states produced by the uncertainty facing many cultural workers, across all three of the industries we studied. Many spoke of nervousness, anxiety and even panic as a regular part of their working lives. One junior cameraman told us of his worries about extended gaps of unemployment between contracts and said that whilst he enjoys being freelance it 'is really insecure because you know it [a big gap in employment] could happen at any point and it's quite a nervous thing to be' (Interview 25). He says, 'I don't know when this contract ends in November whether I'm going to get another one. I just keep thinking if I work hard then it will happen again and I'll get something else' Established cameramen face the same uncertainty: 'not all of us are working all the time. For example, I didn't work for the first 3 months of this year, or I had very little work. But then again, the second half of the year was very busy' (Interview 33). Freelancers in magazines reported spending a lot of time 'chasing up things that you should be paid for' and approaching people for work meaning 'you are constantly living sort of on the edge' (Interview 32, writer men's magazines). One music writer described how a sudden change in the amount of work coming in, precipitated by a drop in regular work for a single title, has resulted in some months without work, sending him to 'that dark place where I panic - "I'm never going to work again and it's impossible to earn a living and I should go and get a [proper] job really"working at a bank or something' (Interview 46). Despite having been a freelance writer for almost ten years this respondent reports: 'I've never got used to the fact that I don't have work ... I don't think you get used to not earning a wage'. Or take this senior freelance music journalist who describes a fall off in the amount of work that had recently come his way:

'In a sense I haven't got significant work at the moment, it's quite weird. "Superb" [as an editor had described his last major feature article] leads to no commissions in the last month. No substantial leads I mean. I've had loads of bits and pieces, but what you like is to have one big feature you're working on and then the bits and pieces.' (Interview 36 )

'One of the worries', he says, 'is always that ... I'm not going to work again'. Few workers we interviewed, even those with salaried staff positions, seemed immune from such feelings of insecurity.

However some magazine writers set these worries about money and employment against the relative freedom that freelancing provided them. As one men's magazine writer says 'on the flipside I can go and have a round of golf on a Monday morning and I couldn't do that if I was five days a week with a regular income' and 'I know a lot of people who are really unhappy in their nine to five work' (Interview 32). Another freelance men's magazine writer emphasised the downsides of stability: 'I don't have any pension, I don't have many holidays, but then it's kind of okay though because I've got a great job. I would like to obviously have some more time off and to spend some more time with my children, but I think it's infinitely better than spending 12 months a year on a job that I hated' (Interview 28).

One music journalist described his working conditions as involving freedom, but 'a very complicated version of freedom' (Interview 4). While this writer worked freelance, the same is true of other cultural workers, including salaried employees, who in general may have more autonomy than workers in other industries, but whose autonomy comes at a cost. As Banks (2007:55) puts it, 'to be (or appear to be) in control of one's destiny is what encourages workers to endorse the systems put in place to expedite flexible production'. Drawing on the work of Knights and McCabe (2003:1588) who posit that 'Employees welcome a sense of self-organization; for when individuals organize their (our) own work it becomes more meaningful', Banks argues that the offer of autonomy 'is sufficiently powerful to override any misgivings, constraints or disadvantages that might emerge in the everyday reproduction of this highly competitive and uncertain domain' (2007:55)

Cultural workers seem torn over the precariousness of their work - bemoaning the mental and emotional states produced, but also resigned to insecurity, and prepared to speak of it as necessary and even desirable. How do they cope? Some spread the risk by working in multiple sites to supplement income. One producer of arts programmes described how reductions in the commissioning of arts programmes have made it necessary for her to take on freelance work as a production manager for factual and children's television companies despite having her own artsbased production company (Interview 53 ). In the music industry, a jazz drummer outlined a familiar situation for musicians, whereby, because it is hard to get regular work, he had to take on teaching to supplement his income:

'The reality is you're not earning your living from gigs ... I can think off the top of my head of one person who doesn't teach on the circuit, in Oxford. But of course he takes every single gig going. I suppose on the more 
positive side of my relationship between doing other types of work in music, was always that sense of I didn't really want to be doing every rubbish gig, and [without the teaching] l'd be forced to do that.' (Interview 63)

Another jazz musician told us that 'if you don't mind a bit of risk in your life you do a certain kind of job and if you like a very stable regular life you do another kind of job' (Interview 10). Bu the 'risk' she refers to is not always sustainable. In television, for example, a factual producer reported that 'quite a few people have left because they found it ... just too uncertain' (Interview 21). And as another producer suggested 'with telly it's never a job for life, so you have always got to be thinking about what else you might do' (Interview 52)

\section{Socialising, networking and isolation}

In this next section, we explore the ambivalence of the sociality of cultural production. Workers discussed in detail the rituals of socialising with their colleagues but questions were raised as to the blurring of boundaries between socialising for pleasure and networking for work. Also, even with the emphasis on regular socialising and networking in these industries, a number of workers reported feeling isolated from both colleagues and their profession.

\subsection{Socialising and networking}

In all the industries we studied, there was a strong sense that the contacts which eventually lead to contracts rely on sociability. For example, in many companies there was a ritual of going to the pub on a Friday night after work or, in the magazine industry, to 'celebrate' going to press. Nixon and Crewe (2004:137-139) describe a culture of hedonism in magazine publishing and the advertising industry noting that 'it was drinking with colleagues after work in the local pub on Friday nights, as well as frequently in the week, that formed a more regular social ritual for both sets of media practitioners'. This was confirmed in our research. A reviews editor for a music magazine reports that:

after we go to press we go out for a pint and to me and to the art director that's really important because the last week is all stress and panic and adrenaline going you just really want to go and have a pint or two, a glass of wine, two glasses of wine, go home on the bus. (Interview 30)

And such social events often bring people together from different parts of the same company, such as creative and marketing personnel: 'If you are based with the editorial team and they are going to the pub on a Friday night, you are naturally going to go with them because you are part of a team' (Interview 47, men's magazine marketer).

For those who are less inclined to such forms of sociability, however, this emphasis on post-work bonding can be difficult. Many workers described themselves as 'not a socialiser' (Interview 59, drama producer) and while recognising the importance of networking and socialising with industry colleagues prefer not to engage in the pub culture. But not identifying as a 'pub person' can be a problem as this camera operator explained:

'You see, I'm not a pub man, and I think there are lots of cameramen or lots of crew who are pub people, and I've never been into that pub culture. So the problem I have is that even when you are out on location, as soon as you finish everybody wants to go to the pub and get drunk, and I've never been into that so that's probably put me as a bit of an outsider in that sense.' (Interview 33)

He describes his lack of interest in the drinking culture of production crews as a 'downfall' an says 'maybe I'd get a lot more work if I was a pub person'. And as a black worker, the pub as a primary site of socialising is perhaps doubly problematic given both the highly racialised nature of these spaces and of an industry which is, as this interviewee says, 'dominated by white males' (Interview 33).

The music industry is, as one might expect from the close links of its products with pleasurable sociality, particularly prone to such a mingling of work and hedonistic leisure. For some in the music industry, including music journalists, socialising is a compulsory element of a job which still has a focus on collective experience, such as live gigs, launches and so on. One artist manager felt there was simply no choice about whether to go out: 'Probably two or three nights a week we are out at gigs, wherever that might be.... Normally if you've got an act that's on tour you will see a gig in London and we always try and encourage everyone to go and see them somewhere else in the country as well.... So you are out a lot and yes, it is very sociable.' (Interview 49)

The consequences of not participating in such a culture are varied. Another artist manager described to us how not being a 'pub person' contributes to a marginalised position:

'The network is very, very important, but I think personally there are better ways to maintain and build a network than going out and getting pissed at gigs, and I've never really been part of that scene. As a result, I'm very much excluded from a big area of the business, but that's a choice l've made about how I wanted to be and how I wanted to work.' (Interview 63)

By making that choice this manager feels he is excluded from certain powerful cliques that have developed around the scene and not belonging to these means 'you don't get a look in': 'So if I were to take a new band to a label, I wouldn't really know where to begin at this point because I'm not really part of any of those scenes' (Interview 63 ). But on the other hand he feels that he is not limited by this exclusion 'because ultimately if they are interested they are going to find you'. There were also questions of work-life balance to

\section{...we see the blurring of pleasure and obligation, freedom and constraint. The blurring of networking and socialising means it becomes very difficult to maintain a boundary around working life.}

be taken into account: 'I'd rather be at home with my wife and kids than out getting drunk with a bunch of people I didn't particularly like, chasing a deal that I didn't believe was right for the band' (Interview 63)

Even in less 'glamorous' occupations such as trade magazine journalism, the expectation to socialise was strong. A junior reporter (Interview 44) described the visits to the pub as 'an extension of work hours really' and said that often 'talk can revolve around work' which can be frustrating on days where 'you want to switch off' but, she says, 'it's actually genuinely fun as well'. Here again we see the blurring of pleasure and obligation, freedom and constraint. The blurring of networking and socialising means it becomes very difficult to maintain a boundary around working life. One series producer in the factual programming genre said that although he would like to keep his work and 'private life' separate, 'the nature of telly normally encourages you actually to bleed your work into your personal life, because that's how you build up contacts, how you get jobs...' (Interview 52).

As one music reviews editor (Interview 30) put it, networking is 'important for the freelance part of the job'. But although it tends to happen outside of work hours it isn't necessarily pleasurable because 'lots of people are never off so you can't relax and socialise with them'. 'Never off': all hours become work hours. This also points to anxieties about the authenticity of friendships in this world of work. As a men's magazine writer puts it: 'T tend to socialise with my editors in London once every two or three weeks, and I pretend that it's me being pally with them, but it's not really, it's me just maintaining relationships' (Interview 28) This kind of 'schmoozing' (Interview 41, music writer), might not be enjoyable but is regarded a important because part of networking socially is letting people "know who you are without making it too blatantly obvious that you want them to help you out ... I do sometimes go for drinks with people, but l'm guessing that is pretty much the definition of networking. That is how a lot of people do get work and do get new jobs and things like that.' (Interview 41)

In the magazine industry, says this writer, networking is implicit and covert. 'People just being friendly with each other, just having a drink and being casual' is networking masquerading as socialising:

'you are basically being friendly under the guise of networking ... it's like an unspoken thing where people are being friendly and being friends and you all invite each other out to things. At the end of it you are kind of saying 'do you want to do this?' or something. (Interview 41)

We are describing working worlds which in many respects seem to conform to Andreas Wittel's depiction of a new 'network sociality' on the basis of his observations of new media workers in London, characterised by many of the features of individualization in modern societies, such as high degrees of mobility and increasing 'choice' about relationships; but also, as Wittel points out, intense but fleeting contact between people, and an assimilation of work and play (though we are not sure that this will become 'the paradigmatic social form of late capitalism', as Wittel (2001:71) speculates). Moreover, we found evidence of many relationships that went beyond ephemerality. The difficult conditions under which creative work is carried out can also lead to friendships that can enable workers to cope with the insecurity and precariousness of creative work Take this documentary producer's description of the friendship he has developed with a fellow producer:

'We're very close friends and we don't get together to talk about work anymore, we usually talk about wine. He's a great wine expert. But I'm very close friends with [him] because we've worked together and we've been driving through the night, we've faced huge difficulties, and it's an interesting thing about this process that when you've been really up against it in a really bad situation, it might be a violent situation, it might be just the plane didn't arrive and you've got to drive 200 miles to the next place and the conditions are cold or difficult, or it might be that you have to turn something around in no time at all. There could be 1001 things but you go through these really, really intense emotional experiences, and if the person you are working with is able to match your energy and actual drive or maybe exceed it, then you develop a bond, you've been through some powerful experience.' (Interview 37)

\subsection{Isolation}

Our interviewees, then, reported many ambivalent experiences of the intense sociality of cultural work. This was the case not only for those working as part of culture-making organisations, but also for freelancers and short-term workers, who need to maintain contacts. But many freelancers also reported a strong sense of isolation. For one of the music writers we spoke to one of the hardest things about being a freelancer is the isolation: 'you don't talk to anyone and you don't see anyone' (Interview 46). This can be 'crippling' as it has a powerful impact on motivation: '[I'm] filling my day sometimes, even when I've got things to do,

[with] very random things ... they get me nowhere ... and at the end of the day I have this mild sense of self-loathing that I've done nothing useful today'. He links this to his personality:

'I am a born worrier, which probably means I'm not the best person to be a freelance. I am concerned about where the work is coming from, I'm concerned about where the work is going, whether my career path has any direction, and it's quite difficult when you are isolated to get reassurances because you don't see other people. You look at other people and think "how come you've got all that work, where is mine?"' (Interview 46)

The music writer we quoted earlier (Section 3 ), who referred to his work as involving 'a very complicated version of freedom', was referring to the fact that he didn't have to 'commute or work in an open plan office or deal with moody colleagues' (Interview 4). But the temptation was to take this freedom too far. He says:

'I can write my copy in my pants if I want to but at 
the same time it often feels like I don't get very far away from my computer for days at a stretch and that something as simple as getting a paper from the corner shop can just not happen for up to a week. And I literally, you know, will not leave this flat for like three days.' (Interview 4)

He observed that up until a few years ago it was almost expected by magazines that the freelance writers would go to the office fairly regularly. At the time he didn't quite understand the importance of this but now, after spending the last couple of years in isolation, he reflects on the value of regular office visits:

'It was beneficial to you because they saw you there, you seemed to get more work, they seemed to remember your existence. But often you'd just think "what am I going to the [magazine] office for? I have no good reason to be there".' (Interview 4)

In 'the connexionist world' that Boltanski and Chiapello (2005:111-112) identify as central to modern work, 'a natural preoccupation of human beings is the desire to connect with others, to make contact, to make connections, so as not to remain isolated'. In an effort to combat the isolating conditions of freelance journalism, one men's magazine writer (Interview 28) rents a desk in the office of a design agency which is located in a regional 'creative industries' precinct. But whilst a location in such an office space can help to reduce isolation, workers can still feel removed from others in the same profession. As a music writer emphasised:

'It's the same with all magazines; l've never met anyone who works on them. I wrote for Esquire for two years and never met anyone. On and off I wrote maybe five or six pieces for them spread over a two year period, but I never met anyone.' (Interview 46)

He says that a positive side of this is that you avoid a magazine's office politics 'but then on the other hand you don't see the fun and games of office life'. For some television workers the issue becomes not isolation from one's profession but isolation from those external to working life. A freelance producer describes how a sense of alienation can occur when spending so much time with a production team; and here the links to selfexploitation are apparent again:

'During the productions, [...] it's impossible to make arrangements in terms of seeing people.I think ultimately your friends get a bit fed up of you neve turning up, and so you end up not bothering to ring them, and then actually you are so knackered when you finish the day you want to come back and chill out anyway really, rather than racing off down the pub. So, I think there is a kind of alienating aspect to the lifestyle, which means you tend to spend more time with the people that you work with because they similarly... I mean that's not true. I mean you're obviously not completely alienated, but I think it doesn't always work that well.' (Interview 21)

On the basis of our interviews, then, it seems that isolation, in its various guises, continues to be a danger for most freelance cultural workers.

\section{Conclusions}

Our main aim in this article has been to build on recent studies of working conditions in the cultural industries by paying more sustained attention to the experiences and conditions of cultural workers, and to do so across three different industries, representing different 'logics'. Our research suggests that these experiences are at best highly ambivalent. This was the case across all three of the industries we studied as we found no evidence that particular industries or genres produced more positive or negative experiences than others. The high levels of casualisation to be found in all three industries led to expressions of victimisation and anger on the part of many workers; a sense of being on the receiving end of harsh and aggressive treatment. Furthermore, long working hours were combined with a sense of responsibility for agreeing to take on such hours. This is troubling when one considers that the great 'army' of freelancers sustaining the cultura industries have little access to the financial and psychological benefits accruing from strong union representation. Understandably, these conditions manifested themselves in the form of considerable anxiety on the part of cultural workers. Whilst some workers highly valued the freedom purportedly offered by the cultural industries, as our title suggests this freedom is complicated because it involves a very strong sense of ambivalence for many workers. Pleasure and obligation become blurred in a highly challenging way. Another area in which ambivalence was strongly manifest was the requirement to socialise and network. There is a very strong culture of hedonism associated with much creative work and this brought with it burdens for those not inclined to the dominant forms of sociality. The evidence we present above in Section 4 suggests that this has age and ethnic dimensions, though this needs exploring more in future research (as do gender dimensions). Conversely - or perhaps linked to that fact - many workers reported experiences of isolation. Against this, however, other workers emphasised the very real friendships formed in cultural work.

Here, then, in reporting on the aspects of our study related to working conditions and experiences, our emphasis has been on the way that our findings provide broad support for the analysis of problems and ambivalences identified by writers such as Banks, McRobbie, Ross and Ursell. Of course, such ambivalent experiences may seem delightful compared with some of the brutal conditions faced by workers across the world, including the world's wealthiest economies (see Ehrenreich, 2001, for a brilliant journalistic exploration of the conditions faced by maids, shop assistants, waitresses and other workers in the USA). This suggests the need to locate our concerns within broader ethical debates about 'good work' and elsewhere, we confront broader theoretical and historical questions of what the conditions and experiences of contemporary cultural work mean for normative conceptions of labour in modern societies, and of whether autonomy and pleasure might be conceived ultimately as tools of control, encouraging self- exploitation (Hesmondhalgh and Baker, forthcoming).

There is a further reason for considering cultural workers besides contributing to our knowledge of their conditions and experiences. Creative industries policy has strongly suggested that jobs in the cultural industries offer better experiences than those older jobs - partly through invocation of buzzwords such as 'creativity' and 'innovation' and that this partly justifies the use of public support to fund the expansion of these industries. It is only through a proper consideration of the experiences available to such workers that such policies can be assessed. As we explained in our discussion of methods, our aim is to use qualitative work to cast light on experiences and responses in the cultural industries. In so doing, we hope to complement the more generalisable findings generated by the quantitative studies referred to at the very beginning of this piece. The quality of working life available in this growing sector may not be as good as many would hope.

\section{Funding source}

The research reported in this article was funded by the Art \& Humanities Research Council, grant \#112075 'Creative

\section{Acknowledgements}

We are grateful to two of the three reviewers for helpfu comments and to the editor of Poetics for his meticulous care.

\section{References}

Banks, M., 2007. The Politics of Cultural Work. Palgrave Macmillan, Basingstoke.

Blair, H., 2001. 'You're only as good as your last job': the labour process and labour market in the British film industry. Work, Employment \& Society 15, 149-169.

Boltanski, L., Chiapello, E., 2005. The New Spirit of Capitalism. Verso, London.

Burawoy, M., 1979. Manufacturing Consent. University of Chicago Press, Chicago.

Carlyon, L., 2006. The issue that won’t go away. Broadcast 22 23, 11 August.

Dex, S., Willis, J., Paterson, R., Sheppard, E., 2000. Freelance workers and contract uncertainty: the effects of contractua changes in the television industry. Work, Employment Society 14, 283-305.

DiMaggio, P., 1977. Market structure, the creative process and popular culture: towards an organizational reinterpretation of mass-culture theory. Journal of Popula Culture 11, 436-452.
Donzelot, J, 1991. Pleasure in work. In: Burchell, G., Gordon, C., Miller, P. (Eds.), The Foucault Effect: Studies in Governmentality. Harvester, London, pp. 262-281.

Ehrenreich, B., 2001. Nickel and Dimed: On (Not) Getting By in America. Owl Books, New York.

Ekinsmyth, C., 2002. Project organization, embeddedness and risk in magazine publishing. Regional Studies 36, 229-243. Faulkner, R., Anderson, A., 1987. Short term projects and emergent careers: evidence from Hollywood. American Journal of Sociology 92, 879-909.

Freidson, E., 1990. Labors of love in theory and practice: a prospectus. In: Erikson, K.T., Vallas, S.P. (Eds.), The Nature of Work: Sociological Perspectives. Yale University Press, New Haven

Gall, G., 1997. The changing relations of production; union derecognition in the UK magazine industry. Industrial Relations Journal 29, 151-162.

Gill, R., 2002. Cool, creative and egalitarian? Exploring gender in project-based new media work. Information and Communication Studies 5, 70-89.

Golding, P., Murdock, G., 2005. Culture, communications an political economy. In: Curran, J., Gurevitch, M. (Eds.), Ma Media and Society. fourth ed. Arnold, London, pp. 60-83.

Hesmondhalgh, D., 2005. The production of media entertainment. In: Curran, J., Gurevitch, M. (Eds.), Mass Media and Society. fourth ed. Arnold, London, pp. 153-171. Hesmondhalgh, D., Baker, S., 2008. Creative work and emotional labour in the television industry. Theory, Culture and Society 25, 97-118.

Hesmondhalgh, D., Baker, S., 2010. Creative Labour: Media Work in Three Cultural Industries. Routledge, London.

Huws, U., 2006-2007. The spark in the engine: creative workers in a global economy. Work Organisation, Labour \& Globalisation 1,1-12.

Knights, D., McCabe, D., 2003. Governing through teamwork: reconstituting subjectivity in a call centre. Journal of Management Studies 40, 1587-1619.

Knights, D., Willmott, H., 1989. Power and subjectivity at work: from degradation to subjugation in social relations. Sociology 23, 535-558.

Kunda, G., 1991. Engineering Culture: Control and Commitment in a High-Tech Corporation. Temple University Press, Philadelphia.

McRobbie, A., 2002. Clubs to companies: notes on the decline of political culture in speeded up creative worlds. Cultural Studies 16, 516-531.

Menger, P.M., 1999. Artistic labor markets and careers. Annual Review of Sociology 25, 541-574.

Menger, P.M., 2006. Artistic labour markets: Contingen work, excess supply and occupational risk management. In: Ginsburgh, V.A., Throsby, D. (Eds.), Handbook of the Economics of Art and Culture. Elsevier, pp. 765-811.

Miège, B., 1989. The Capitalization of Cultural Production. International General, New York.

Murdock, G., 2003. Back to work: Cultural labor in altered times. In: Beck, A. (Ed.), Cultural Work: Understanding the Cultural Industries. Routledge, London, pp. 15-36.

Neff, G., Wissinger, E., Zukin, S., 2005. Entrepreneurial labo among cultural producers: "Cool" jobs in "hot" industries. Social Semiotics 15, 307-334.

Nixon, S., Crewe, B., 2004. Pleasure at work? Gender consumption and work-based identities in the creative industries. Consumption, Markets and Culture 7, 129-147.

Paterson, R., 2001. Work histories in television. Media Culture \& Society 23, 495-520.

Ross, A., 2003. No-Collar: the Humane Workplace and Its Hidden Costs. Temple University Press, Philadelphia.

Ryan, B., 1992. Making Capital from Culture. Walter de Gruyter, Berlin and New York

Saundry, R., Stuart, M., Antcliff, V., 2007. Broadcasting discontent-freelancers, trade unions and the Internet. New Technology, Work \& Employment 22, 178-191.

Shaw, P., 2004. Researching artists' working lives. Arts Research Digest 30 (special research feature lift-out). Towse, R., 1992. The labour market for artists. Richerce Economiche 46, 55-74.

Ursell, G., 2000. Television production: issues of exploitation, commodification and subjectivity in UK television labour markets. Media, Culture \& Society 22, 805-825.

Willis, J., Dex, S., 2003. Mothers returning to television production work in a changing environment. In: Beck, A (Ed.), Cultural Work: Understanding the Cultural Industries. Routledge, London, pp. 121-141.

Wittel, A., 2001. Toward a network sociality. Theory, Culture and Society 18 (6), 51-76

“'A Very Complicated Version of Freedom': Condition and Experiences of Creative Labour in Three Cultural Industries" was originally published in Poetics: Journal of Empirical Research on Culture, the Media and the Arts, 38 (1): pp4-20. 